\title{
The Biomimicry Design Lens Method Applied to the Development of a Temporary Pavilion Inspired by the Victoria Amazonica
}

\author{
Elton Cristovão da Silva Lima ${ }^{1}$, Cristina Matsunaga ${ }^{2}$, Leticia Teixeira Mendes ${ }^{2}$ \\ ${ }^{1}$ Universidade Federal do Rio de Janeiro, Brasil \\ elton.lima@fau.ufri.br \\ 2 Universidade Federal de Pernambuco, Brasil \\ criismnaga@gmail.com \\ leticia.mendes@ufpe.br
}

\begin{abstract}
Combining Biomimicry and Parametric Design, this research aims to detail the design process of an ephemeral pavilion which uses the method Biomimicry Design Lens, proposed by Biomimicry 3.8. The experiments developed in this paper followed the method's diagram insights and it was guided by the 'Biology for Design' diagram in a non-sequential order in the design process. The pavilion is located in the Serpentine Gallery, and it was bio-inspired by the ribs of the inferior face of the Victoria amazonica leaf, a natural morphological structure that was translated into a quadrangular grid characteristic of the waffle structure. Finally, the parametric implementation allowed the development of several morphological experiments.
\end{abstract}

Keywords: Biomimicry, Parametric Design, Temporary Pavilion, Biomimicry Design Lens, Victoria amazonica

\section{Introdução}

A arquitetura, atualmente, enfrenta o desafio de atualizar seus paradigmas incorporando práticas mais sustentáveis e mais eficientes tendo em vista o acelerado desenvolvimento tecnológico. Nesse contexto, o objetivo desta pesquisa é documentar as etapas do processo experimental e das possibilidades do design bio-inspirado na concepção de um pavilhão efêmero para a Serpentine Gallery. A abordagem projetual adotada combina a modelagem paramétrica e o método Biomimicry Design Lens proposto pelo Biomimicry 3.8 cuja inspiração natural explorada foi a vitória régia. 
Segundo Benyus (2006), a biomimética é uma disciplina que estuda elementos e estratégias da natureza com o intuito de inspirar soluções de problemas humanos seguindo os preceitos de sustentabilidade e eficiência de recursos. O design bio-inspirado é uma área de estudo promissora, e aplicada à arquitetura possibilita o desenvolvimento de ideias através de padrões morfológicos naturais e permite desenvolver a criatividade, já que um novo contexto é apresentado para desenvolver ideias logicamente fundamentadas.

Este trabalho se debruça sobre a botânica que também é uma importante fonte de inspiração para profissionais que trabalham com a biomimética, sendo um campo complexo que envolve diversos organismos. A espécie escolhida foi a Vitória-Régia pertencente à espécie Victoria amazonica. A característica dessa planta utilizada como inspiração para o projeto do pavilhão foram as nervuras, presentes na face inferior da folha, que possui estrutura em malha radiada com aspecto lembrando o couro (Figura 1) (BIOVERDE02, 2013).

Por conseguinte, com o desenvolvimento tecnológico na área da arquitetura, vê-se o design paramétrico como um meio de aumentar a produtividade e ainda assim desenvolver projetos contemporâneos com certo grau de complexidade. Assim o experimento do pavilhão foi desenvolvido tridimensionalmente no Grasshopper que, por sua vez, é um plug-in que usa o software Rhinoceros como visualizador da geometria implementada no seu ambiente de programação visual.

Segundo Brod, Pires e Borba (2012), esta ferramenta opera com algoritmos generativos de modelagem associativa através da linguagem de programação visual que constrói geometrias a partir da conexão de componentes e parâmetros. Essa ferramenta permite explorar a geração de múltiplas variações de formas em um curto espaço de tempo, através da modificação de apenas alguns parâmetros.

Dessa forma, muitos laboratórios de design computacional no mundo têm buscado aliar essa abordagem projetual à biomimética e ao desenvolvimento de pavilhões efêmeros que servem como canteiro de obra e recinto para experimentação e aprimoramento de técnicas e uso de materiais inovadores. De acordo com Quintella et al. (2016), estes objetos arquitetônicos, devido ao forte caráter experimental e interativo, possibilitam o estudo e expansão de paradigmas relacionados à ocupação de espaços públicos à concepção da forma arquitetônica.

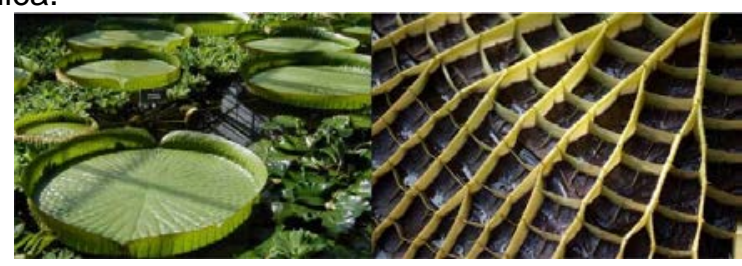

Figura 1. Vitória-Régia à esquerda e sua estrutura nervurada à direita. Adaptado de Puffin11k e Wikimedia, 2009. 
A Serpentine Gallery foi o local escolhido para o desenvolvimento deste experimento por ser uma das mais importantes galerias britânicas e já abrigar um programa de pavilhões temporários. Localizada em Kensington Gardens, foi pioneira com o programa de pavilhões de verão em que uma galeria de arte encomenda anualmente projetos arquitetônicos efêmeros. Este experimento considera os pavilhões como produtos arquitetônicos. Apesar de também ser uma expressão escultural, o pavilhão Vitória-Régia é uma estrutura concebida para estimular a permanência de pessoas e conta com espaço para café e eventos, mas sem abdicar da flexibilidade dos arranjos espaciais e possibilidade de reorganização ao mobiliário.

\section{Metodologia}

O pavilhão bio-inspirado na Vitória-Régia se encaixa na estratégia solutionbased (baseada na solução) que, de acordo com Badarnah (2012), primeiramente é encontrada uma estratégia na natureza que pode ser aplicada para resolver qualquer problemática.

O método utilizado seguiu o Biomimicry Thinking - Biomimicry Design Lens (Pensamento Biomimético - Lentes do Projeto Biomimético), que consiste num processo de projeto biomimético que utiliza diagramas, desenvolvidos por Janine Benyus (BIOMIMICRY 3.8, 2015), intuitivos capazes de guiar o projetista da ideia inicial ao produto final considerando diversas variáveis com caráter sustentável.

Foram usados dois diagramas fixos propostos pelo Biomimicry Design Lens, o Diagrama dos Elementos Essenciais e o Diagrama dos Princípios da Vida. Posteriormente, optou-se por seguir o Diagrama Biologia para o Design por apresentar maior liberdade de percurso das etapas durante o processo, e por ter sido necessário regredir algumas etapas para novos ensaios e então progredir com o experimento.

\subsection{Processo de projeto}

O pavilhão bio-inspirado seguiu o método Biomimicry Design Lens, em que cada diagrama leva o projetista a uma reflexão responsável que se desdobra ao longo do projeto biomimético. O primeiro passo, chamado de Diagrama dos Elementos Essenciais (Figura 2a), estimula a conexão do homem com a natureza de forma a levá-lo a inspirações preocupadas com a sustentabilidade no planeta. Impulsiona o desenvolvimento de empatia pelo meio natural ressaltando a importância da ética, respeito e gratidão pelo ambiente.

O segundo passo do processo de projeto considera o Diagrama dos Princípios da Vida composto por seis fundamentos básicos para que a vida proporcione condições favoráveis à própria vida (Figura 2b). Esse diagrama norteou as tomadas de decisões projetuais do pavilhão. 


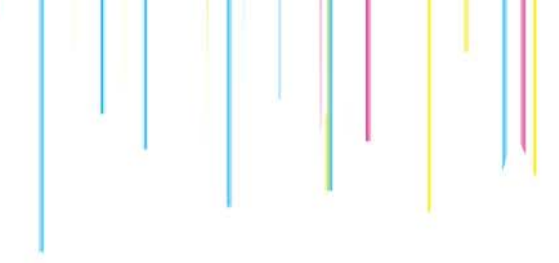

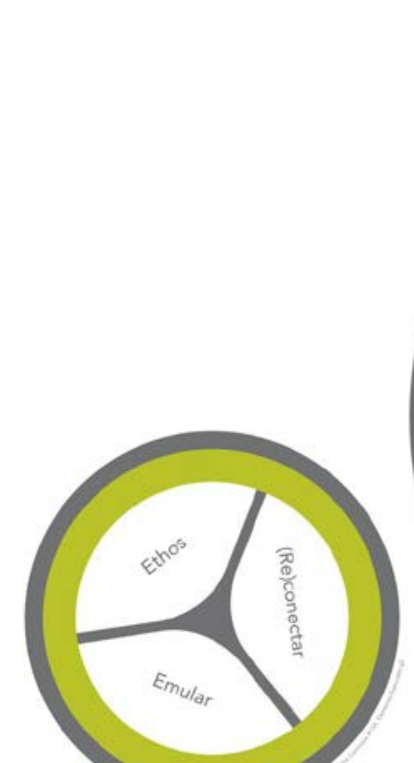

(a)

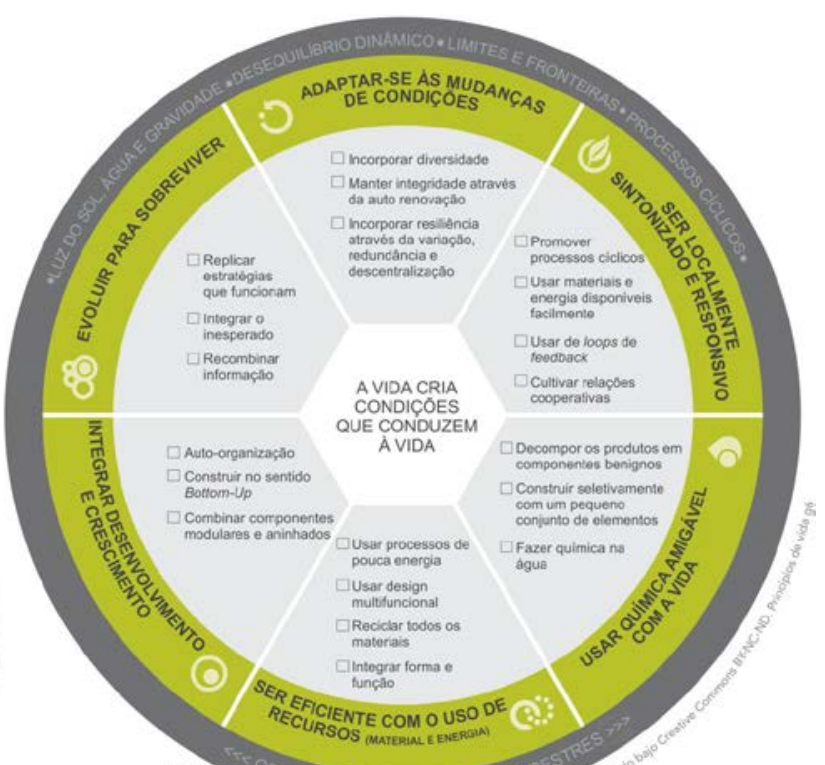

(b)

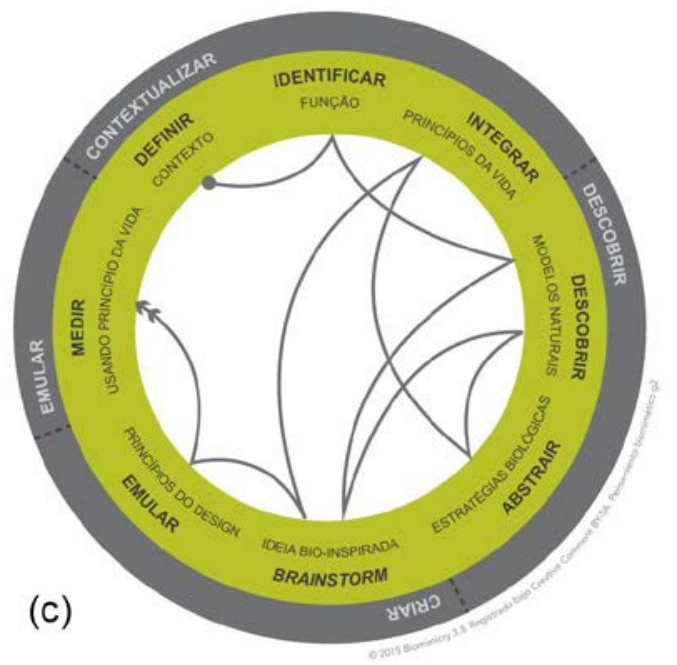

Figura 2. Diagramas Biomimicry Design Lens utilizados nesta pesquisa. Adaptado de Biomimicry 3.8, 2015.

1 - Evoluir para sobreviver. Responsável pelo gerenciamento de informações e uma abordagem inovadora em que se expõe informações para produzir o projeto; possibilita fazer testes, identificar erros e fazer melhorias através de mudanças de parâmetros.

2 - Adaptar-se às condições de mudança. Da concepção à fabricação há o estudo para o melhor aproveitamento das formas, de modo que ela seja 
adequada para o melhor funcionamento do projeto. Além disso, neste momento é possível explorar os processos mais adequados de acordo com a função proposta.

3 - Ser atento e responsivo localmente. Foi estabelecido que o pavilhão seria uma estrutura de madeira, fabricada de modo sustentável, que permitisse ajustes ao longo do processo através de protótipos em escala reduzida.

4 - Usar química amigável à vida. Neste ponto decidiu-se que o pavilhão e todos os seus elementos usariam poucos materiais - majoritariamente cimento queimado para o piso e madeira para a estrutura. Outra premissa seria de que nenhum produto tóxico seria utilizado e os encaixes seriam previstos computacionalmente nas próprias peças estruturais.

5 - Ser eficiente no uso de recursos materiais e energéticos. No Pavilhão Vitória-Régia, a forma foi pensada para desempenhar a função estrutural, composta de grandes placas de madeira que se sustentam (em caso de reciclagem podem dar origem a outros elementos menores - como mobiliários urbanos). A fabricação digital, através de fresadoras CNC, permite fazer cortes paralelos ao material e na diagonal (dimensão referente à espessura) levando em consideração os desbastes, evitando assim o desperdício de matériaprima. Além disso, seria importante que o pavilhão ter baixo consumo energético, enfatizando o ideal de sustentabilidade. Para isso, o projeto apresenta uma proposta aberta horizontalmente que facilita o fluxo de ventos e a utilização de iluminação natural

6 - Integrar desenvolvimento e crescimento. No projeto, seria importante que houvesse a possibilidade de organização das partes que compõem o pavilhão, permitindo que o processo de fabricação e montagem fosse estruturado desde o início. Permitindo que ainda na fase de concepção e testes fosse possível organizar todas as peças, enumerá-las e mapear o local de encaixe, favorecendo a compreensão do funcionamento do todo.

Em seguida, na terceira fase da abordagem biomimética, foi importante contextualizar como a biomimética seria trabalhada no processo de projeto, seguindo etapas de contextualização (definição de escopo), descobertas, criação e avaliação.

Esta fase integra a estratégia natural ao design, sendo definida pelo Diagrama do Pensamento Biomimético. A abordagem não é rígida e permite percorrer o diagrama de modo não sequencial (Diagrama Biologia para o Design - Biology to Design) ou sequencial (Diagrama do Desafio à Biologia Challenge to Biology), sendo a primeira a abordagem utilizada nesta pesquisa. Assim, não foi seguido um raciocínio linear no diagrama, partindo-se de ideias que foram surgindo ao longo do processo, sendo, às vezes, necessário voltar às etapas anteriores para concluir a ideia em andamento (Figura 2c).

O terceiro diagrama resulta em 8 processos:

1 - Definir. Projeto de pavilhão de exposição e eventos para instalação anual Serpentine Gallery Pavilion em Londres/Inglaterra. Estrutura temporária que seria exibida por aproximadamente 3 meses, com estrutura de rápida montagem e considerando conceito aberto. 
2 - Identificar. O pavilhão seria construído com a finalidade de ser um elemento arquitetônico de destaque na exposição da galeria. Serve como espaço público durante o dia abrigando um café, e à noite se transforma em palco de eventos artísticos, debates e conferências.

3 - Descobrir. Fase de investigação de características e formas, além de tentar abstrair mentalmente a ideia pessoal de o que é a Vitória-régia e sua morfologia.

4 - Brainstorm. Neste passo surgiram as primeiras. Cogitou-se uma superfície orgânica contínua, com várias alturas e raios, remontando à diversidade do tamanho das folhas da Vitória-Régia. A segunda ideia seria uma estrutura semienterrada com pilares formados por ripas de madeira entrelaçadas e uma rampa que levasse à um mirante, referindo-se aos espinhos ao longo do caule da planta e a resistência da folha em suportar peso.

5 - Descobrir. Percebeu-se a necessidade de voltar à etapa de pesquisa para investigar curiosidades e informações científicas, o que poderia ajudar na abstração a partir dos detalhes morfológicos e funcionais da planta.

6 - Abstrair. A atenção foi direcionada para as nervuras na face inferior da folha e a possível relação estrutural que este elemento desempenha biologicamente sustentando uma grande folha. Além disso, a partir da percepção da forma contínua como o caule se desdobrava nas várias nervuras surgiu a ideia de que isso poderia ser emulado arquitetonicamente.

7 - Integrar. Posteriormente foi tomada a decisão de que o pavilhão seria uma inspiração das nervuras da Victoria amazonica. Então, foi necessário integrar os princípios da vida analisados anteriormente e fazer uma racionalização dos aspectos gráficos das nervuras (Figura 3). Considerou-se malha radial com células quadradas.

8 - Brainstorm. O retorno à esta fase foi o início para o processo prático de projeto seguindo as referências biomiméticas. As novas ideias já tinham uma estrutura de pilares orgânicos que se fundiriam em cobertas circulares. Assim, optou-se por usar a estrutura Waffle como partido arquitetônico. A forma orgânica da estrutura (pilar fundido com a coberta) a ser implementada em ambiente paramétrico seria decomposta em uma estrutura baseada numa malha quadrangular. Este processo geraria peças de madeira que se encaixariam entre si para se sustentarem.

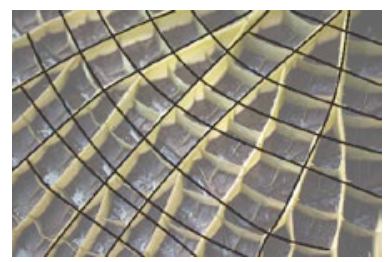

Figura 3. Malha quadricular abstraída a partir das nervuras da Vitória-Régia. Adaptado de Wikimedia, 2009. 
O sistema estrutural Waffle viabiliza a construção ou reconstrução de um objeto 3D a partir de seções planas, painéis de superfície e de cortes radiais. A opção pelo uso deste sistema possibilitou vencer grandes vãos e suportar cargas mais pesadas, além de facilitar a construção de formas orgânicas complexas (Loomis, 2018). Além disso, a estrutura waffle já foi utilizada anteriormente na Serpentine Gallery no pavilhão de 2005, de Álvaro Siza e Eduardo Moura (Serpentine Gallery, 2015).

\section{$3 \quad$ Resultados}

A nona e penúltima etapa seguida no diagrama do Pensamento Biomimético se refere ao Emular. Neste estágio, todas as ideias desenvolvidas na fase anterior foram amadurecidas e implementadas computacionalmente utilizando o Grasshopper. Os objetos tridimensionais foram modelados separadamente - pilar e coberta circular - por meio de circunferências com raios e inclinações diferentes (Figura 4a) e posteriormente houve a junção como um só objeto paramétrico que logo seria submetido à um seccionamento (Figura 4b) para gerar as placas de madeira que compõem a estrutura waffle (Figura 4c). Uma possibilidade de material com que o pavilhão poderia ser produzido seria a madeira Kerto, como utilizado no projeto do Metropol Parasol em Sevilha/Espanha com estrutura semelhante (Holanda, 2012).

A projeção da estrutura no terreno demarca a sua área de implantação, rebaixada $90 \mathrm{~cm}$, dando um aspecto de anfiteatro ao pavilhão e deixando o equipamento mais baixo em relação à galeria.

Neste processo é possível a alteração do design, controle dos espaçamentos das nervuras e suas espessuras de forma rápida e intuitiva, através de barras de rolagem numéricas que controlam as funções implementadas no código (Figura 5). Devido a esta facilidade de geração de formas (após a conclusão do código), foram testadas diversas combinações de parâmetros e adequações da malha estrutural, possibilitando a criação de diferentes soluções de projeto, porém para esta pesquisa foram documentadas apenas 5 (Tabela 1).

O código, aqui representado em forma de diagrama, foi dividido em 9 partes que manipuladas possibilitam desenvolver diversas formas do pavilhão.

A - A implementação paramétrica do pavilhão partiu da construção de 3

(a)

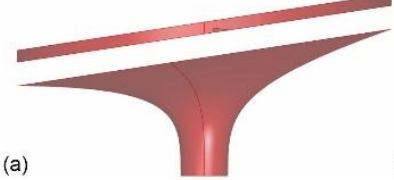

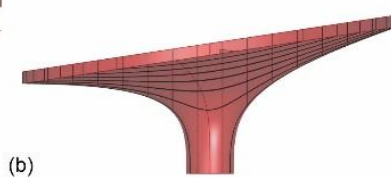

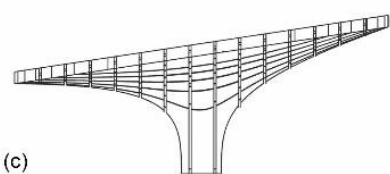

Figura 4. Processo de modelagem de uma das estruturas do pavilhão. 

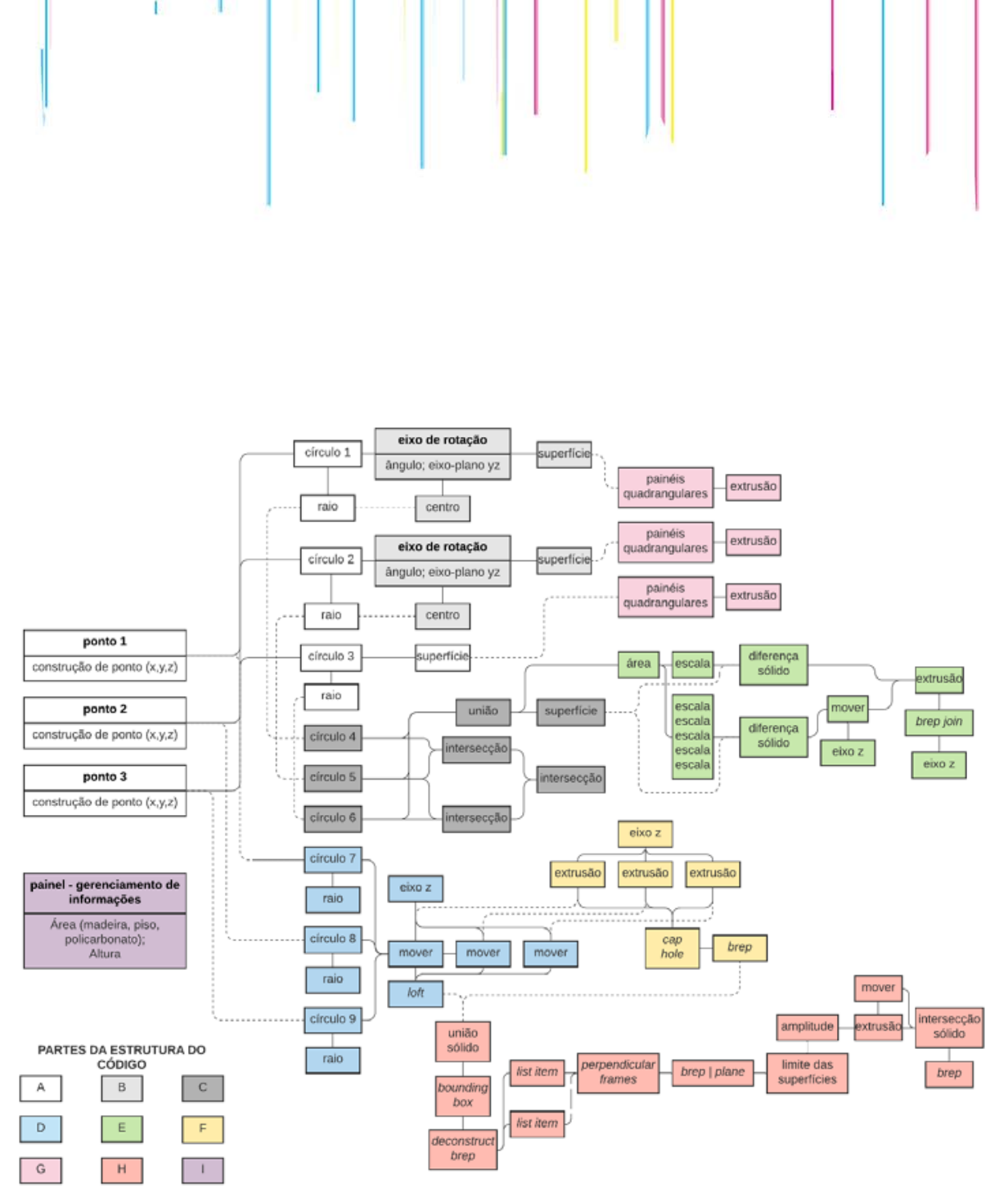

Figura 5. Diagrama UML do código implementado no Grasshopper.

pontos que possibilitaram formar 3 círculos de diferentes alturas que correspondem à geometria básica das estruturas.

B - É possível movimentar esses círculos no eixo yz, permitindo incliná-los e gerar uma superfície.

C - Foram criados mais 3 círculos, como projeção dos primeiros, no piso. Estes sofreram intersecção para criar uma única superfície e formar a base do pavilhão.

D - Utilizou-se os mesmos 3 pontos construídos anteriormente e criou-se mais 3 círculos correspondentes às bases das colunas. Estes foram replicados no eixo $z$, e em seguida foi gerada uma superfície conectando os círculos para formar o corpo da coluna.

E - A superfície do piso sofreu algumas modificações de escala a partir no eixo z negativo (para baixo), criando degraus para uma base semienterrada.

F - O topo das colunas foi fechado, e sofreu extrusão no eixo $z$, criando uma cobertura de $50 \mathrm{~cm}$ unindo-se ao corpo dos pilares e gerando um elemento único.

G - Foi criada uma malha quadrangular que se tornaria os painéis de policarbonato que fariam o fechamento vertical da estrutura.

$\mathrm{H}$ - As 3 estruturas desenvolvidas passaram pelo processo de divisão perpendicular aos eixos $x$ e $y$, e posteriormente sofreram extrusão. Foram 
criados cortes verticais nas peças com regulagem da amplitude, gerando os encaixes da estrutura waffle.

I - Foram implementados painéis de gerenciamento de informações conectados a componentes do código que permitiram visualizar e quantificar as áreas de madeira, piso e policarbonato, assim como identificar alturas e raios.

O código implementado permitiu desenvolver uma série de experimentos utilizando o mesmo raciocínio biomimético. Assim, para este artigo, foram documentadas apenas 5 possibilidades morfológicas do pavilhão Vitória-régia.

Dos 5 experimentos, o primeiro possui a maior área $\left(429,78 \mathrm{~m}^{2}\right)$, enquanto o segundo possui a menor $\left(284 \mathrm{~m}^{2}\right)$. O conjunto de estruturas do experimento 4 é o mais alto $(7,63 \mathrm{~m})$, enquanto o experimento 2 é o mais baixo $(3,50 \mathrm{~m})$. Os experimentos 4 e 5 possuem estruturas com as maiores inclinações (31\%), enquanto as propostas 2 e 3 não possuem estruturas inclinadas. A cobertura com maior raio $(8 \mathrm{~m})$ é apresentada no experimento 1 , enquanto as de menor raio $(5 \mathrm{~m})$ fazem parte das propostas 2 e 4.

O experimento 1 possui coluna com maior raio de base $(100 \mathrm{~cm})$, enquanto o terceiro possui o menor raio $(60 \mathrm{~cm})$. Em todos os casos a profundidade do nível semienterrado foi de $90 \mathrm{~cm}$. O experimento que precisaria da maior quantidade de madeira para construção é o terceiro $\left(996,42 \mathrm{~m}^{2}\right)$, enquanto o experimento 4 é o que menos necessita $\left(826,23 \mathrm{~m}^{2}\right)$.

É importante ressaltar que todos os valores apresentados na tabela podem ser alterados gerando novos experimentos de acordo com a configuração definida. Quanto à questão estrutural, assim como a Serpentine Gallery e tantos outros programas de pavilhões efêmeros, é importante considerar a necessidade de uma equipe multidisciplinar de arquitetura e engenharia para desenvolver um dimensionamento preciso. Esta pesquisa buscou abordar o processo de projeto biomimético integrado ao desenvolvimento paramétrico com o intuito de gerar múltiplas soluções morfológicas.

\section{Discussão}

A última fase do processo de projeto (10 - Medir), permite relacionar os resultados com as premissas estabelecidas anteriormente através dos princípios da vida. Assim, foi possível estabelecer uma comparação satisfatória do resultado do pavilhão dado o estudo e abstração morfológicos da VitóriaRégia. A estrutura dos pilares-coberta waffle se relaciona com a forma das nervuras e remonta ao pecíolo sustentando a folha da planta. A composição de elementos circulares de dimensões variadas remonta à variedade no tamanho das folhas de Vitória-Régia. 
Tabela 1. Tabela de parâmetros e valores implementados no Grasshopper.

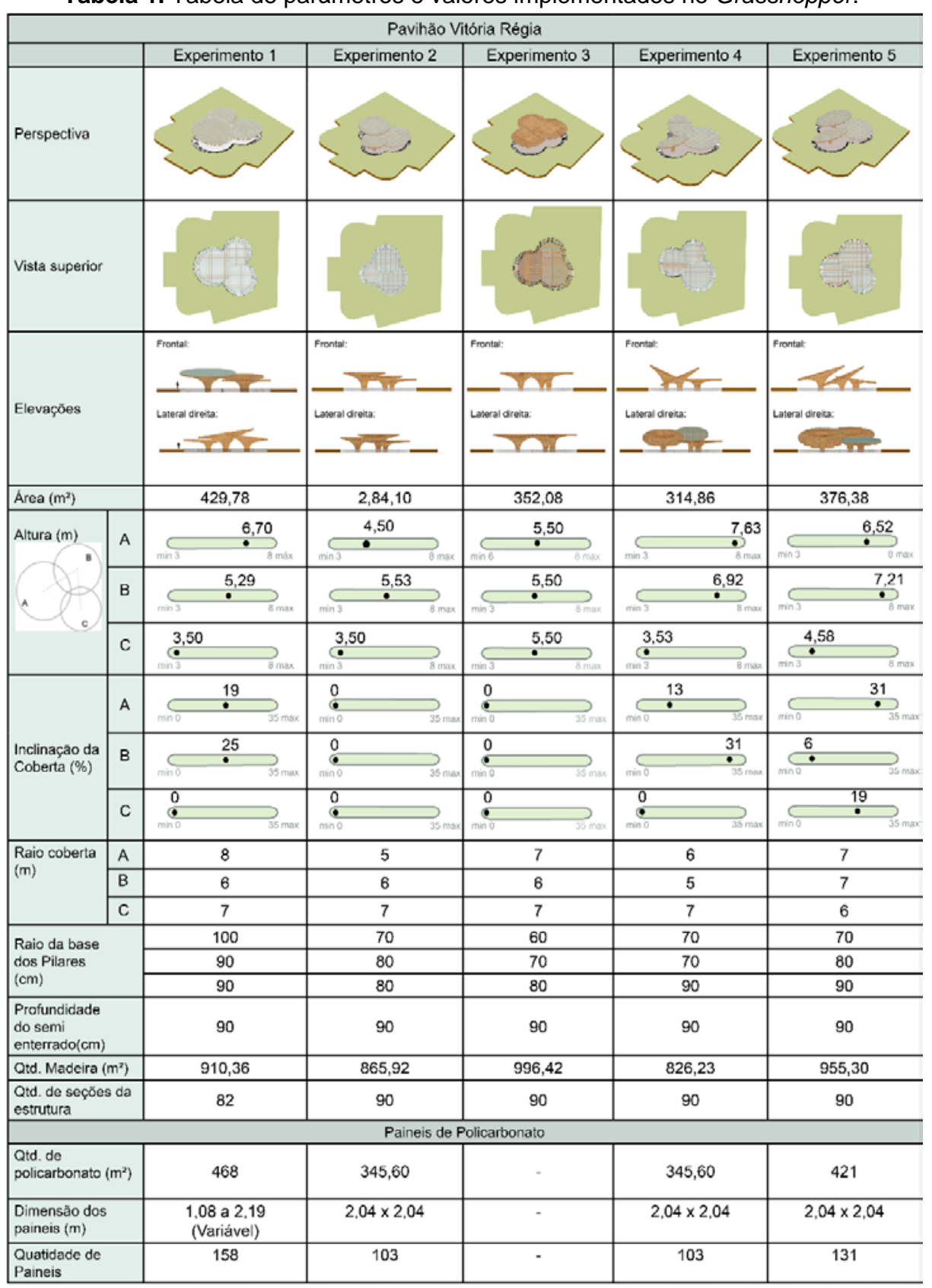

Ao comparar os resultados com as aspirações pontuadas no desenvolvimento do Diagrama dos Princípios da vida percebe-se 0 
cumprimento das premissas. O processo de fabricação por meio da fabricação digital é o adequado, otimizando o material e gerando o mínimo de desperdício, sendo, portanto, um meio sustentável. A montagem do pavilhão é consideravelmente mais rápida do que se fosse utilizado outros sistemas estruturais. Não é necessário usar produtos tóxicos e a forma desempenha a função estrutural.

Diante disso, a escolha da Serpentine Gallery como local de construção do pavilhão Vitória Régia foi estratégica pois é um local que valoriza o desenvolvimento de espaços funcionais, com apelo estético, mas que incentiva a utilização de materiais e métodos construtivos não convencionais.

Para a melhoria do projeto documentado e continuação do desenvolvimento dessa pesquisa, seria interessante adicionar plug-ins que possibilitassem a análise e simulação em tempo real da estrutura e do conforto ambiental, por exemplo. Esses dados possuem o potencial de auxiliar ainda mais na adaptação da bio-inspiração principalmente durante a fase inicial de projeto, já que parâmetros ambientais e estruturais mais precisos seriam incorporados ao código.

Quanto ao design paramétrico, apesar da possiblidade de manipulação de parâmetros e da geração de múltiplas formas a partir de um mesmo código implementado, sistemas generativos só são capazes de selecionar bons projetos caso haja domínio do problema e suas definições sejam extremamente bem definidas (Fischer \& Herr, 2001).

\section{Considerações Finais}

A partir do experimento do pavilhão Vitória Régia, fica claro a possibilidade de integração entre a metodologia de projeto baseada na biomimética e a modelagem paramétrica. A biomimética é uma área da ciência que requer o estudo de elementos da natureza e a abstração de estratégias e funções muitas vezes subjetivas - nesta fase surge a ideia que fundamenta o projeto, a partir da inferência de dados e padrões encontrados na natureza.

Além disso, os diagramas do Biomimicry Design Lens se demonstraram uma metodologia de projeto eficiente, permitindo uma reflexão mais profunda sobre o impacto que desejamos que o projeto cause no planeta e combinado com a modelagem paramétrica se demonstrou uma forma de projetar muito mais interativa e com resultados formais mais complexos. Essas metodologias combinadas expandem o campo de referências iniciais para projeto e permite materializar computacionalmente as ideias e fornecer inúmeros resultados de modo ágil a partir da mudança de parâmetros pré-estabelecidos.

O experimento se adequa a proposta de uma tipologia arquitetônica de pavilhões que exigem flexibilidade e por muitas vezes qualidade escultórica, e no caso de ser inserido na Serpentine Gallery e possibilidade de testar 
